\title{
The Subcooling Effect of the Flue Gas Flow Mixture Internal Dynamic and Heating Capacity
}

\author{
Žilvinas ULDINSKAS*, Vytautas DAGILIS** \\ *Kaunas University of Technology, Faculty of Mechanical Engineering and Design, Studentu st. 56, LT-51424 Kaunas, \\ Lithuania, E-mail: zilvinas.uldinskas@ktu.edu \\ **Kaunas University of Technology, Faculty of Mechanical Engineering and Design, Studentu st. 56, LT-51424 Kaunas, \\ Lithuania, E-mail: vytautas.dagilis@ktu.lt \\ cross ref http://dx.doi.org/10.5755/j02.mech.26583
}

\section{Introduction}

Nowadays European energy sector is arguably well invested in biomass (wood fuel) industry in compliance with recent regulations (mainly directive 2010/75/EU) issued by the EU. However, it is still conceivably not reaching full potential. Even though the wood fuel is less effective than fossil fuels, it has moderate calorific value and is widely available. The main issue is that energy production process generates a substantial amount of wasted energy (the majority being flue gases). With the help of condensing economizers, that amount is fairly well regulated, which keeps the process as efficient as it is possible in this very moment. Nevertheless, emitted flue gases are still above the ambient temperatures $\left(\sim 50^{\circ} \mathrm{C}\right)$, which would mean that this low-grade energy can be harnessed with the help of additional equipmentnamely heat pumps.

To achieve greater energy efficiency in energy generation process additional investments and additional energy sources are required. The implementation of chemical heat pumps according to Lu Y. et al. and Donnelan et al. $[1,2]$ requires additional heat energy - primary and cheap energy source, as well as the cooling capacity of the heat pumps can also be used like a solitary instance as indicated by Wang L. et al. and Kumar M. et al. [3, 4]. Hebenstreit et al. $[5,6]$ express that the mechanical heat pumps need electrical or mechanical energy source. In the Dagilis V. et al. article [7] other type of low-grade heat potential utilization is discussed; water vapour of the flue gas could be regenerated in a mass transfer regenerator, i.e., transferred from flue gases to air which is blown towards a burning chamber. In all instances, the low-grade utilization requires additional effective means, be that economic, energetic or both. Energy efficiency depends on recovered heat value proportion, comparing it with amount of the used energy, thus depends on coefficient of performance of the heat pump.

It is obvious that transformation of all waste heat of the plant is not rational, mainly because the heat capacity is gradually decreasing while flue gas temperature is lowering. Because of this, more detailed calculations of the lowgrade heat amount must be developed. In previously mentioned articles, only Hebenstreit et al. [5, 6] suggest some graphics of wood fuel waste heat calculations. Nonetheless, the authors do not present mathematical model which is needed to analyse the flue gas heat and mass flow in additional heat exchanger which is important in analysing the heating potential of supercooled flue gas (the gas mass flow, for example, is dependent on temperature when it is below the dew point, because water vapour converts into liquid).
In this article the algorithm for evaluating flue gas components below flue gas mixture's dew point is presented which is essential in finding how much of low-grade heat energy can be utilized in additional heat utilisation processes (i.e. with the application of heat pump). This article is also a continuation study of the flue gas parameter calculations which purpose was to devise the algorithm for flue gas component calculations in superheated state [8].

For the flue gas component calculations (namely water vapour $\left.\left(\mathrm{H}_{2} \mathrm{O}\right), \mathrm{O}_{2}, \mathrm{CO}_{2}, \mathrm{~N}_{2}\right)$, wood burning process was analysed with different values of wood fuel moisture $(w=45 \%, 50 \%, 55 \%$ and $60 \%)$ and several air excess values $(\lambda=1.2,1.5,1.8)$ were taken into account. The low-grade heat value that could be recovered is calculated via $50 \%$ biofuel moisture $w$ and previously mentioned air excess values $\lambda$ when fuel energy input is $1 \mathrm{MW}$.

\section{Calculation method for cooled flue gas components}

Heat capacity of flue gas depends on mass flow $g^{w}$ and enthalpy difference between higher and lower temperatures.

$$
Q^{w}=g^{w}\left(h_{1}^{w}-h_{2}^{w}\right)
$$

If the temperature of flue gases is above the dew point (superheated state), calculation of mixture enthalpy is quite simple if mass proportions of the components are known (2). However, if the temperature is lower (i.e., flue gas is subcooled, calculation of the $h^{W}$ is much more complicated. The amount of water vapour decreases with lowering temperature; thus, the concentrations of other components increase. The total mass flow including condensate does not change, only internal balance of water vapour and condensate changes. Since the enthalpy of the condensate $h_{f}^{H 2 O}$ is much lower than the vapour enthalpy $h^{H 2 O}$, the value of mixture $h^{W}$ becomes lower because the decreasing temperature results in more condensate. In this instance, the flue gas enthalpy is calculated according Eq. (3).

$$
\begin{aligned}
& h^{W}=\bar{m}^{\mathrm{CO} 2} \times h^{\mathrm{CO} 2}+\bar{m}^{O 2} \times h^{O 2}+\bar{m}^{N 2} \times \\
& \times h^{N 2}+\bar{m}^{H 2 O} \times h^{H 2 O}, \\
& h_{t} s^{w}=\bar{m}_{t s}^{C O 2} \times h^{C O 2}+\bar{m}_{t s}^{O 2} \times h^{O 2}+\bar{m}_{t s}^{N 2} \times h^{N 2}+ \\
& +\left(\bar{m}^{H 2 O}-\bar{m}_{t s}^{H 2 O}\right) \times h_{f}^{H 2 O} .
\end{aligned}
$$


There is only one mass proportion, i.e. primary water vapour concentration in superheated mixture $\bar{m}^{H 2 O}$ that does not depend on temperature $t_{s}$ in this equation, while other concentrations vary as a result of the water vapour change. Water vapour mass proportion below $t_{s}$ is calculated using Eq. (4):

$$
\bar{m}_{t s}^{H 2 O}=\bar{v}_{t s}^{H 2 O}\left(\mu^{H 2 O} / \mu_{t s}^{H 2 O}\right),
$$

where: the $\bar{v}_{t s}^{H 2 O}$ is volumetric proportion of water vapour in flue gas; $\mu_{t s}^{w}$ is the flue gas average kilomole mass.

Parameter $\bar{v}_{t s}^{H 2 O}$ or $\bar{p}_{t s}^{H 2 O}$ depends on temperature $t_{w}$ and can be calculated by following Eq. (5):

$$
\begin{aligned}
& \bar{p}_{t s}^{H 2 O}=v_{t s}^{H 2 O}\left(t_{s}\right)=p_{t s}^{H 2 O} / P=6.11 \times 10^{-3} \times \\
& \times E X P\left[17.67 t_{s} /\left(t_{s}+243.5\right)\right] / P,
\end{aligned}
$$

where: pressure $p_{t s}^{H 2 O}$ and $P$ dimensions are in bar.

Kilomole mass of flue gas mixture $\mu_{t s}^{w}$ depends on volumetric concentrations of components $\bar{v}^{n}$ and their kilomole masses. Concentrations $\bar{v}^{n}$, in turn, varies according to wood moisture $w$, air excess value $\lambda$ and, relatively slightly to air humidity- $\varphi$. When flue gas temperatures are below dew point $t_{s}$ and part of water vapour turns into condensate, the additional $\mu_{t s}^{w}$ dependence subject to $t_{s}$ comes into effect. Therefore, the flue gas kilomole mass is designated as $\mu_{t s}^{w}$ instead of $\mu^{w}$, which is for superheated state of mixture (see the Eq. (8)).

The decrease of water vapour volumetric concentration in gas mixture increases other components concentrations proportionally. The $\gamma$ indicates how much volumetric concentrations of $\mathrm{CO}_{2}, \mathrm{O}_{2}, \mathrm{~N}_{2}$ increase, when water vapour concentration decreases from $\bar{v}^{H 2 O}$ to $\bar{v}_{t s}^{H 2 O}$ The coefficient of proportion $\gamma$, kilomole mass of flue gas mixture and kilomole mass in the case of flue gas temperature being above the dew point are calculated after (7), (8) and (9) accordingly:

$$
\begin{aligned}
& \gamma=\left(1-\bar{v}_{t s}^{H 2 O}\left(t_{s}\right)\right) /\left(1-\bar{v}^{H 2 O}\right), \\
& \mu_{t s}^{w}=\bar{v}_{t s}^{H 2 O} \mu^{H 2 O}+\gamma\left(\bar{v}^{C O 2} \mu^{C O 2}+\bar{v}^{O 2} \mu^{O 2}+\bar{v}^{N 2} \mu^{N 2}\right), \\
& \mu^{w}=\bar{v}_{t s}^{H 2 O} \mu^{H 2 O}+\bar{v}^{C O 2} \mu^{C O 2}+\bar{v}^{O 2} \mu^{O 2}+\bar{v}^{N 2} \mu^{N 2} .
\end{aligned}
$$

Expressions of volumetric concentrations of components $\bar{v}^{n}$ are expressed (as the volumetric proportion) in the following manner:

$$
\begin{aligned}
& \bar{v}^{C O 2}=1 / v^{W}, \\
& \bar{v}^{O 2}=1.03(1-\lambda) / v^{W}, \\
& \bar{v}^{N 2}=1.03 \lambda(3.76-\varphi / 0.21) / v^{W} .
\end{aligned}
$$

When water vapour concentration decreases, the relations for volumetric concentrations are more complicated. Using certain temperature $t_{s}$, the concentration $v_{t s}^{H 2 O}$ is calculated by (5) equation and subsequently coefficient $\gamma$ is estimated using the (6). The following balance equation of volumetric concentrations can stand in this case:

$$
\begin{aligned}
& \bar{v}^{H 2 O}+\bar{v}^{C O 2}+\bar{v}^{O 2}+\bar{v}^{N 2}=\bar{v}_{t s}^{H 2 O}+ \\
& +\gamma\left(\bar{v}^{H 2 O}+\bar{v}^{O 2}+\bar{v}^{N 2}\right) .
\end{aligned}
$$

Mass concentrations required for calculating enthalpies by Eq. (3), can be calculated as follows:

$$
\begin{aligned}
& \bar{m}_{t s}^{C O 2}=\gamma \bar{v}^{C O 2}\left(\mu^{C O 2} / \mu_{t s}^{w}\right), \\
& \bar{m}_{t s}^{O 2}=\gamma \bar{v}^{O 2}\left(\mu^{O 2} / \mu_{t s}^{w}\right), \\
& \bar{m}_{t s}^{N 2}=\gamma \bar{v}^{N 2}\left(\mu^{N 2} / \mu_{t s}^{w}\right) .
\end{aligned}
$$

The flue gas enthalpy $h^{W}$ relation includes component enthalpies $h^{\mathrm{H} 2 \mathrm{O}}, h^{\mathrm{CO} 2}, h^{\mathrm{O} 2}, h^{N 2}, h_{f}{ }^{\mathrm{H} 2 \mathrm{O}}$ which are not constant and depend on flue gas temperature $t$. The dependency is almost linear in a $0-300^{\circ} \mathrm{C}$ temperature interval, so their algebraic expressions are presented like a first-degree polynomial:
1) $\left.h^{\mathrm{H} 2 \mathrm{O}}=2.008 t+2472 ; 2\right) h^{\mathrm{CO} 2}=0.976 t+478$
3) $\left.h^{O 2}=0.956 t+520 ; 4\right) h^{N 2}=1.048 t+487$
5) $h_{f}^{H 2 O}=4.22 t-1.40$

\section{Heat value potential of the super cooled flue gas flow}

Heat flow of the low grade flue gases is calculated by Eq. (1), in which the $g^{w}$ is mass flow (kg/s) of the flue gases for boiler heating unit $Q_{i n}$, $(1 \mathrm{MW}$ in this case), or for supply fuel mass flow unit $g_{F}$, in $\mathrm{kg} / \mathrm{s}$. In both cases, the wood fuel heat value, $L H V$ or $H H V$, has to be known.

Owens and Cooley [10] as well as Fransescato and Antonini [9] present similar relations of the average calorific value for both conifers and deciduous trees. Equations are based on experimental and theoretical data. According to Owens and Cooley [10], wet wood calorific value can be calculated by Eq. (17):

$L H V=L H V_{0} \times(1-w)-2.4 w=19.1-21.5 w$.

$L H V_{0}$ is lower heat value of dry wood $(w=0)$, which equals to $19.1 \mathrm{MJ} / \mathrm{kg}$ like an average value for both conifer and deciduous trees [10]. It is clear, that $L H V$ in wet wood greatly depends on wood moisture $w$. If water makes $50 \%$ of total mass, the $L H V$ drops more than twice. If the $H H V$ is applied, the Eq. (17) becomes as:

$$
L H V=\left(H H V_{0}-H H V_{0} \times \bar{m}^{H}\right) \times(1-w)-2.40 w .
$$

$H H V_{0}$ is higher heating value of wood where latent heat of vaporization is taken into account. Average value of $H H V_{0}$ (when $w=0$ ) is $20.3 \mathrm{MJ} / \mathrm{kg}$ [16] and $\bar{m}^{H}$ is hydrogen molar mass part in dry wood that is accepted as 
0.06. $H H V_{0} \times m^{\wedge} H$ is subtracted from the $H H V_{0}$, because it comes from water vapour condensation. The higher moisture $w$, the lower value of the caloric value expressions: $L H V_{0} \times(1-w)$ and $H H V_{0}\left(1-\bar{m}^{H}\right) \times(1-w)$. Caloric value of the wet wood is decreasing also because an additional heat is needed for vaporizing the mass of water that is in physical relation with wood. Specific heat of water vapour is very high $-2.40 \mathrm{MJ} / \mathrm{kg}$.

Fuel supply rate is found in relation with woodfuel power input which in this instance is accepted as $1 \mathrm{MW}$ (19):

$$
g^{F}=1 /(19.1-21.5 w) .
$$

One kilogram of fuel emits $m^{w} \mathrm{~kg}$ of flue gas, hence mass flow of flue gases released from $1 \mathrm{MW}$ of the $Q_{i n}$ is calculated according:

$$
g^{w}=g^{F} m^{w}
$$

Effects of subcooling the flue gas can be examined using the aforementioned equations in finding the flue gas mixture component concentration proportions which determine subcooled flue gas enthalpy values, which in combination with flue gas flow then enables the analysis of potential heat value of cooled gas (1).

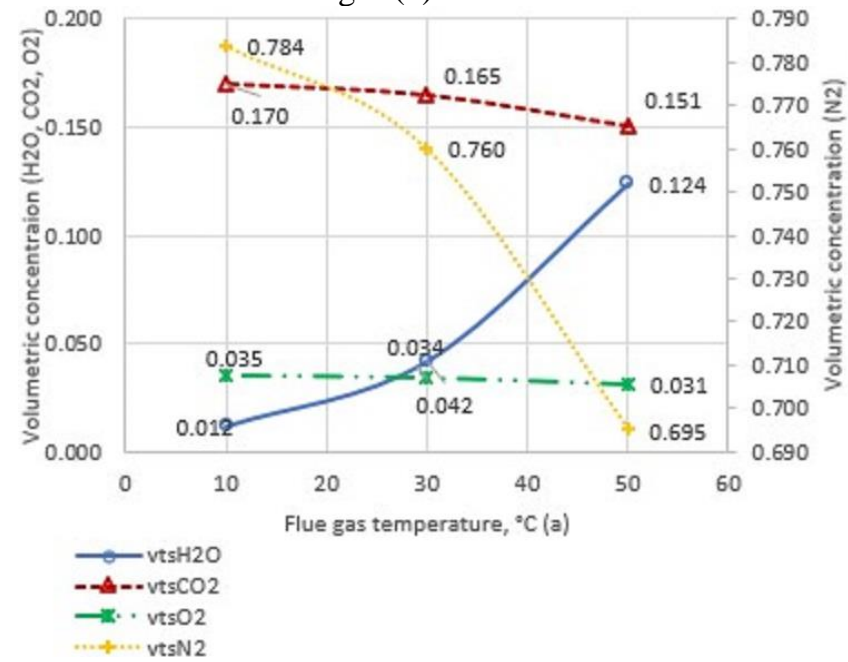

a

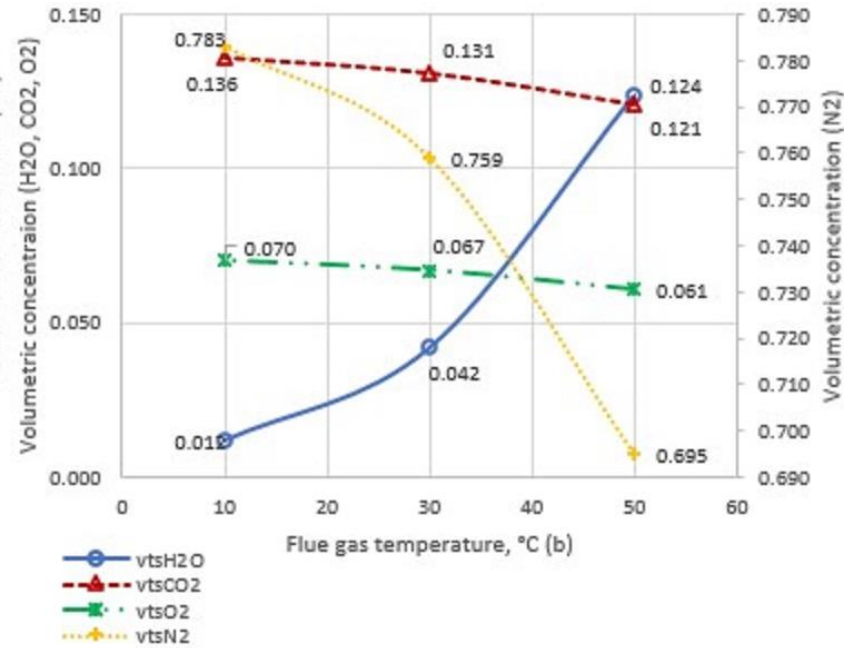

b

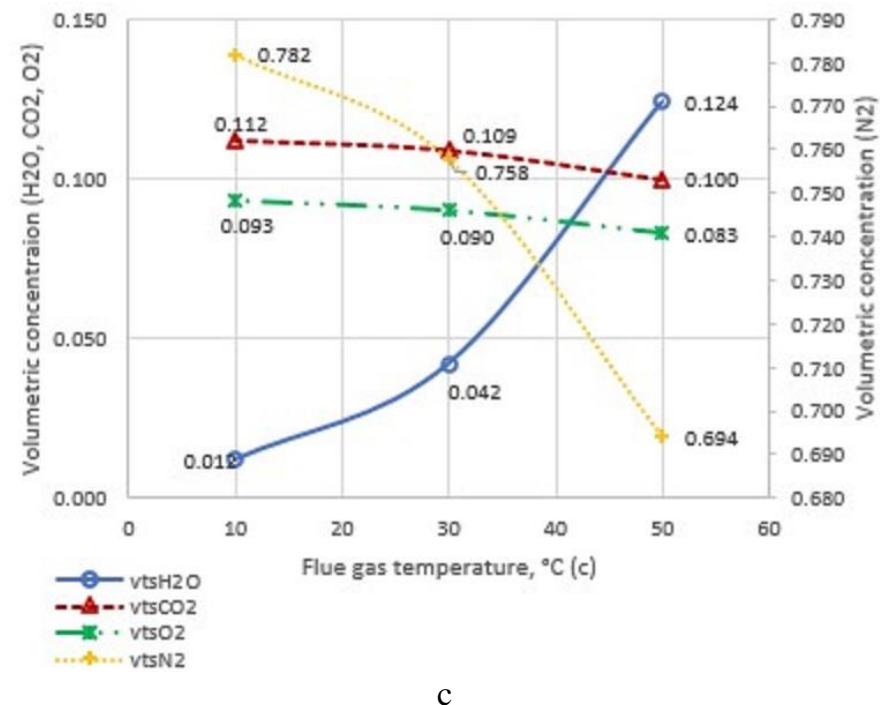

Fig. 1 Variation of the flue gas components volumetric concentration according to flue gas temperature 


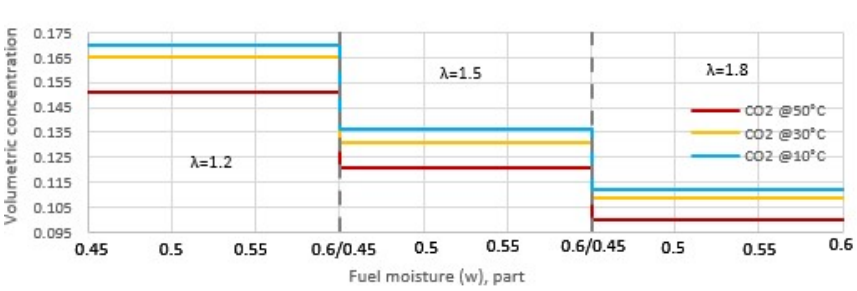

a

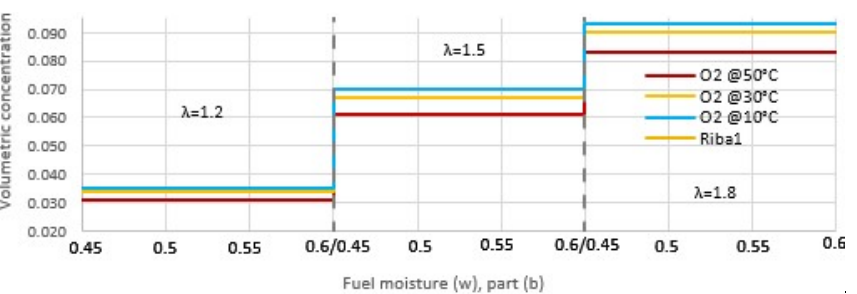

b

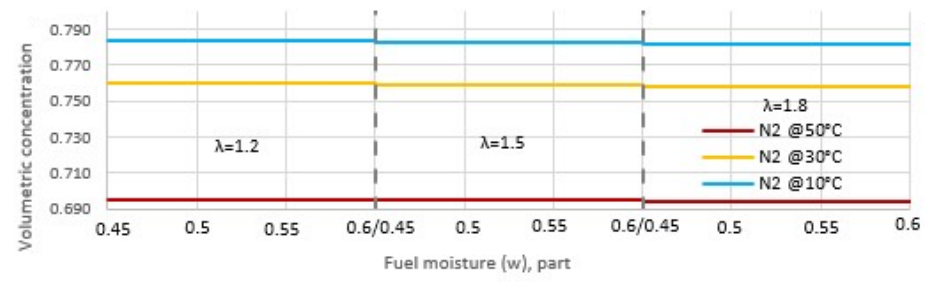

$\mathrm{C}$

Fig. 2 a) Carbon dioxide; b) oxygen and c) nitrogen volumetric dependency on biofuel moisture content

In addition, it also appears that with bigger air excess coefficient tend to change carbon dioxide, nitrogen and oxygen gas concentrations in subcooled flue gas. At $10^{\circ} \mathrm{C}$ $\mathrm{CO}_{2}$ volumetric concentration decreased from $0.170(\lambda=1.2)$ to $0.112(\lambda=1.8), \mathrm{O}_{2}$ increased from $0.035(\lambda=1.2)$ to 0.095 $(\lambda=1.8)$ and $\mathrm{N}_{2}$ volumetric concentration slightly decreased from $0.784(\lambda=1.2)$ to $0.782(\lambda=1.8)$. Fig. 4 shows that the changes in volumetric concentrations have similar nature when flue gas temperature is at $30^{\circ} \mathrm{C}$ and $50^{\circ} \mathrm{C}$. The change in carbon dioxide and oxygen is more visible because the amount of these gases is little compared to nitrogen part in flue gas.

The flue gas mixture enthalpy calculation results are shown in Fig. 3. Calculated values are based on $\lambda=1.2 \div 1.8, w=50 \%$ and flue gas pressure $P=1$ bar as the accepted case. The general trend is that the flue gas enthalpy increases with higher temperature although it does not change gradually: when $\lambda=1.2$ at $65.9^{\circ} \mathrm{C}$ (where the condensation starts) the enthalpy of the flue gas is $906 \mathrm{~kJ} / \mathrm{kg}$ and drastically decreases to $652 \mathrm{~kJ} / \mathrm{kg}$ at $35^{\circ} \mathrm{C}$, the change then becomes slower where the enthalpy reaches $467 \mathrm{~kJ} / \mathrm{kg}$ at $20^{\circ} \mathrm{C}$. At other air excess values 1.5 and 1.8 the trend is similar- enthalpy values decrease from 847 to $481 \mathrm{~kJ} / \mathrm{kg}$ and 805 to $490 \mathrm{~kJ} / \mathrm{kg}$. The visible decrease is non-linear, i.e. more intensive at the start of the condensation.

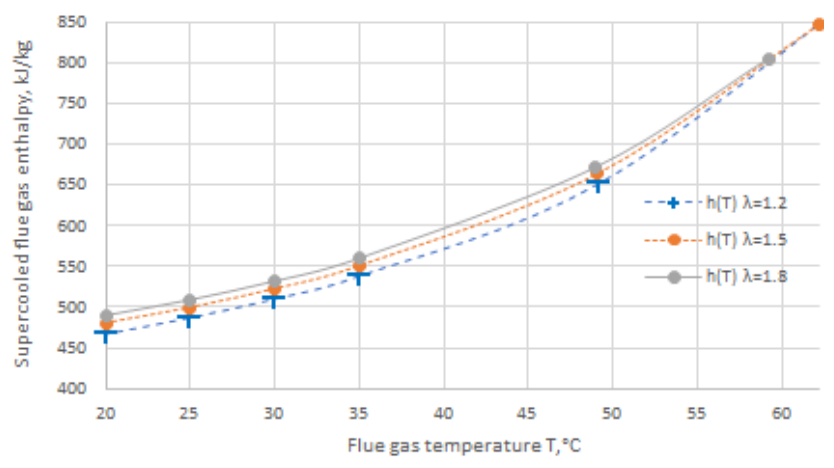

Fig. 3 Flue gas enthalpy subject to subcooling temperature

For given inlet and outlet temperature at the condensing economizer $150^{\circ}-49^{\circ} \mathrm{C}$, heating power $192 \mathrm{~kW}$, $184 \mathrm{~kW}$ and $177 \mathrm{~kW}$ (Figs. 5, a-c base load) of thermal energy can be recovered according to calculations for $1 \mathrm{MW}$ woodfuel energy input $Q_{\text {in }}$ when air excess coefficients are $1.2,1.5$ and 1.8 respectively.

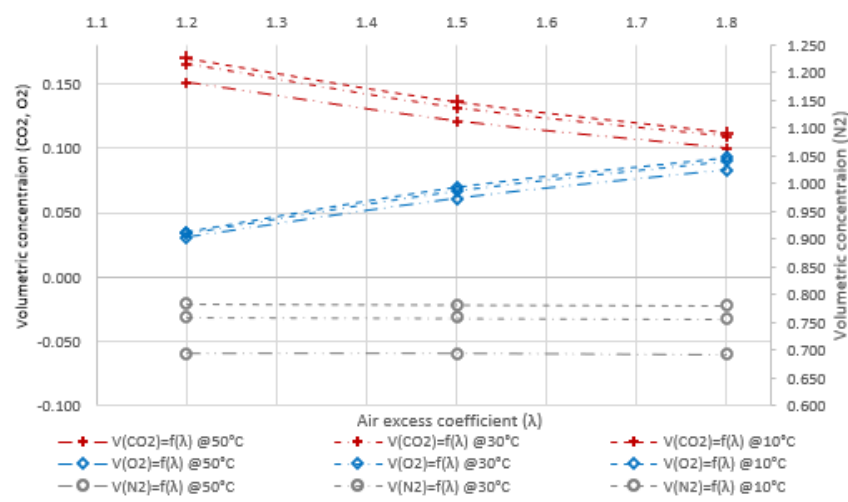

Fig. 4 The volumetric concetrations of $\mathrm{CO}_{2} \mathrm{O}_{2}$ and $\mathrm{N}_{2}$ subject to air excess ratio $\lambda$

Additionally, subcooling flue gas flow down to $35^{\circ}, 30^{\circ}, 25^{\circ}$ and $20^{\circ} \mathrm{C}$ recovers heat values of $62 ; 77.2 ; 89.9$ and $100.8 \mathrm{~kW}$ when $\lambda=1.2$ (Fig. 5, a); 73.5; 91.7; 106.6 and $119.2 \mathrm{~kW}$ when $\lambda=1.5$ (Fig. 5, b); 84.6; 105.5; 122.5 and $136.6 \mathrm{~kW}$ when $\lambda=1.8$ (Fig.5, c) for $1 \mathrm{MW}$ of fuel energy input. It gives the overall gained heat values (additional and economizer heat recovery together) of $254 \mathrm{k} \mathrm{W}\left(35^{\circ} \mathrm{C}\right)$, $269.2 \mathrm{~kW}\left(30^{\circ}\right), 281.9 \mathrm{~kW}\left(25^{\circ} \mathrm{C}\right)$ and $292.8 \mathrm{~kW}\left(20^{\circ} \mathrm{C}\right)$ when $\lambda=1.2 ; 257.5 \mathrm{~kW}\left(35^{\circ} \mathrm{C}\right), 275.7\left(30^{\circ}\right), 290.6 \mathrm{~kW}$ $\left(25^{\circ} \mathrm{C}\right)$ and $303.2 \mathrm{~kW}\left(20^{\circ} \mathrm{C}\right)$ when $\lambda=1.5 ; 261.6 \mathrm{~kW}\left(35^{\circ} \mathrm{C}\right)$, $282.5 \mathrm{~kW}\left(30^{\circ}\right), 299.5 \mathrm{~kW}\left(25^{\circ} \mathrm{C}\right)$ and $313.6 \mathrm{~kW}\left(20^{\circ} \mathrm{C}\right)$ when $\lambda=1$. 8 . It can be observed that heat recovered with flue gas subcooler would be up to around $13 \%$ for $1 \mathrm{MW}$ (1000 $\mathrm{kW} / 136.6 \mathrm{~kW})$ fuel energy input $(L H V)$ in the best case, moreover, combination of economizer and flue gas subcooler heat recovery could result in up to approx. 31\% (1000 $\mathrm{kW} / 313.6 \mathrm{~kW}$ ) in the best case.

Since the temperatures of flue gas are very low in the subcooling process, he recovered heat could only be utilized via heat pumps.

\section{Conclusions}

The algorithm for evaluating biomass woodfuel flue gas flow component concentrations (internal dynamic) and energy parameters when the flue gas is subcooled (i.e. 
when the temperature is lower than the dew point) together with several calculation cases were presented. The basis of the calculations included various wood fuel moisture cases $w-45,50,55$ and $60 \%$ as well as three different air excess values $\lambda-1.2 ; 1.5$ and 1.8 .

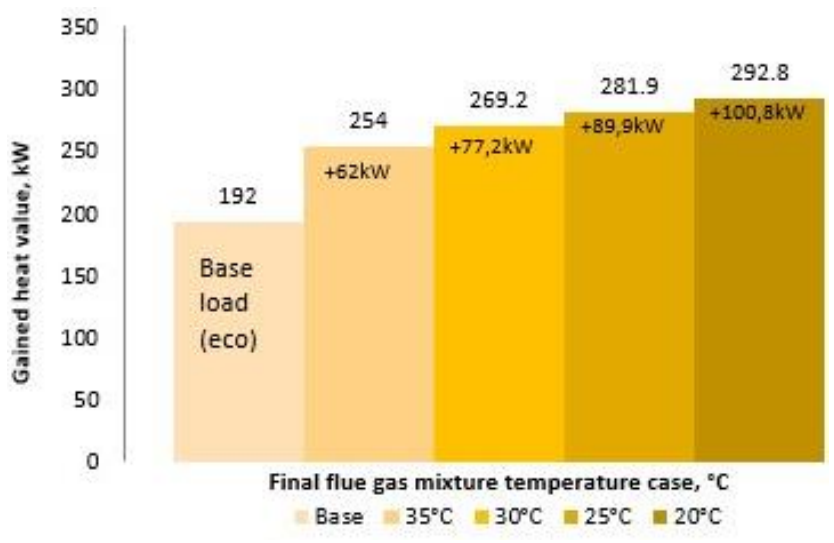

a

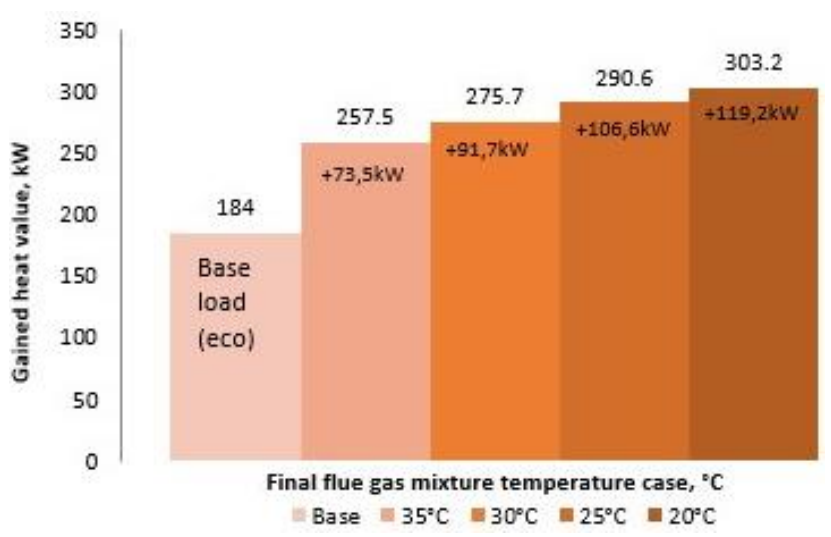

b

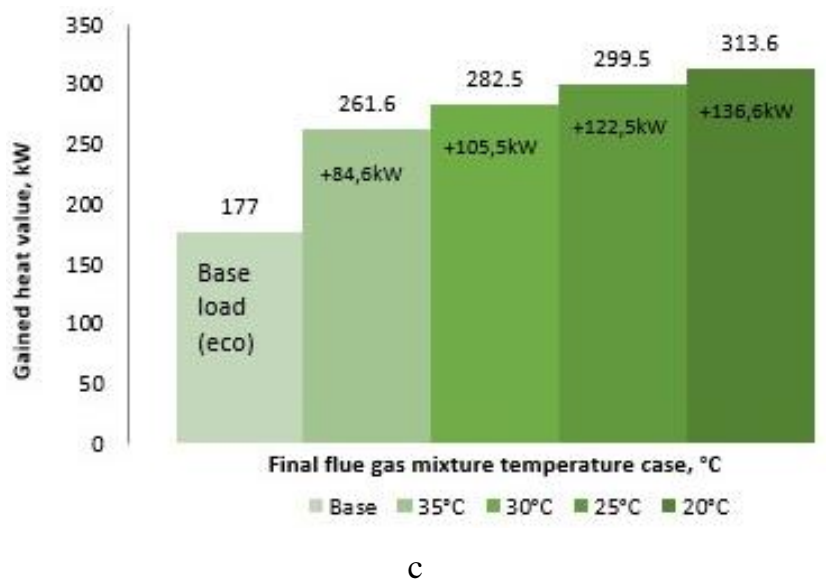

Fig. 5 Gained heat value cases depending on final flue gas temperature

It was determined that the flue gas temperature in the subcooled flue gas affects every component of the flue gas mixture. Increasing flue gas temperature results in higher water vapour amount in flue gas, while other components (such as $\mathrm{CO}_{2}, \mathrm{O}_{2}$ and $\mathrm{N}_{2}$ ) concentrations decrease with increasing temperature.

The effect of the air excess coefficient $\lambda$ is different for every subcooled flue gas mixture component. Water vapour concentration remains constant with any air excess coefficient value. When air excess coefficient increases, changes are visible for other components: $\mathrm{CO}_{2}$ concentration tends to decrease as well as $\mathrm{N}_{2}$ concentration, albeit in comparison $\mathrm{N}_{2}$ change is miniscule. Lastly, bigger air excess value results in higher $\mathrm{O}_{2}$ concentrations.

As opposed to flue gas component concentrations in flue gas above dew point temperature, biofuel moisture content does not influence any flue gas component concentration. Biofuel moisture determines dew point temperature of the flue gas, which in this case is only important to decide calculation points (dew point temperatures) which are used to calculate the enthalpy values (which are decreasing when flue gas is cooler) of the flue gas mixture and subsequently find the potential heat value for flue gas subcooling process.

The potential recoverable amount of energy from the subcooled flue gas was also examined for the $1 \mathrm{MW}$ of fuel input $(L H V)$ in the boiler plant. It was determined that the energy recovery rate could lead to additional $13 \%$ (up to $31 \%$ when usage of the economizer is taken into account) of the produced heat energy in the boiler plant when cooling flue gas after the economizer, however the low temperature of the flue gas means that the waste heat potential could only be utilized only using heat pump.

\section{References}

1. Lu, Y., Bao, H., Yuan, Y., Wang, Y., Wang, L., Roskilly, A. P. 2014. Optimization of a novel resorption cogeneration using mass and heat recovery, Energy Procedia 6: 1103-1106.

https://doi.org/10.1016/j.egypro.2014.11.1032.

2. Donnellan, Ph., Cronin, K., Byme, E. 2015. Recycling waste heat energy using vapour absorption heat transformers: A review, Renewable and Sustainable energy 42: 1290-1304. https://doi.org/10.1016/j.rser.2014.11.002.

3. Wang, L., Ziegler, F., Roskilly, A. P., Wang, R., Wang, Y. 2013. A resorption cycle for cogeneration of electricity and refrigeration. Applied Energy 106: 56-64. https://doi.org/10.1016/j.apenergy.2013.01.041.

4. Kumar, M., Das, R. K. 2017. Experimental analysis of absorption refrigeration system driven by waste heat of diesel engine exhaust. Thermal Science, 2017 OnLineFirst(00), p.3-3. https://doi.org/10.2298/TSCI160311003K.

5. Hebenstreit, B., Schnetzinger, R., Ohnmacht, R., Hoftberger, E., Lungren, J., Haslinger, W., Toffolo, A. 2014. Techno-economic study of a heat pump enhanced flue gas heat recovery for biomass boilers, Biomass and bioenergy 71: 12-22.

https://doi.org/10.1016/j.biombioe.2014.01.048.

6. Hebenstreit, B., Schnetzinger, R., Ohnmacht, R., Hoftberger, E., Haslinger, W. 2011. Efficiency optimization of biomass boilers by a combined condensationheat pump-system, Proceedings of ECOS 2011, Novi Sad, Serbia, July 4-7.

7. Dagilis, V., Vaitkus, L., Balčius, A., Gudzinskas, J., Lukoševičius, V. 2018. Low grade heat recovery system for woodfuel cogeneration plant using water vapour regeneration. Thermal Science 2018 OnLine-First Issue00, p. 81-81. https://doi.org/10.2298/TSCI171020081D.

8. Uldinskas, Z., Dagilis, V. 2019. Evaluation of wood fuel flue gas component concentrations depending on 
temperature, air excess value and fuel moisture, Proceedings of CYSENI 2019, 23-24 May, Kaunas, Lithuania.

9. Francescato, V., Antonini, E. 2008. Wood fuels handbook. Production quality requirements, trading. AIEL.

10. Owens, E., Cooley, S. 2013. Calorific value of Irish woodfuels-Coford.

http://www.coford.ie/media/coford/content/publications/projectreports/cofordconnects/Calo-

rific\%20value \%20of\%20Irish\%20woodfuels..pdf.

\section{Z. Uldinskas, V. Dagilis}

\section{THE SUBCOOLING EFFECT OF THE FLUE GAS FLOW MIXTURE INTERNAL DYNAMIC AND HEATING CAPACITY}

\section{S u m m a ry}

Growing environmental restrictions in energy production industry calls for greater efficiency and cleaner fuel burning processes. Biomass (wood chips) as a fuel is in great demand for boiler and power plants as it is considered widely available and relatively clean. While combining woodfuel flue gas and condensing economizers significantly raises the efficiency and makes it even more viable solution for energy production although the biomass fuel usage still has reservations in waste heat, which could be utilized. The calculation algorithm is presented for evaluation of subcooled biomass flue gas components concentration values which determine the leftover heat energy value carried by flue gas flow. Several cases of biomass quality (regarding moisture $w=45 \%, 50 \%, 55 \%$ and $60 \%$ ) and combustion process quality (regarding air excess value $\lambda=1.2$; $1.5 ; 1.8$ ) in the flue gas temperature range of 50 to $20^{\circ} \mathrm{C}$ and effects for flue gas internal dynamic were examined. It was determined that water vapour amount depends only on temperature, while every other component concentration change with different air excess and temperature values. It was observed that further usage of biomass flue gas could result in up to $13 \%$ additional heat energy recovery for $1 \mathrm{MW}$ of fuel input, system combination together with condensing economizers could result in up to $31 \%$ of heat energy recovery.

Keywords: woodfuel, waste heat, flue gas component dynamic, low grade heat. 